\title{
Ethical Questions Arising from A Psychiatrist Suicide
}

\author{
Khaled Mohamed, MD* \\ Interim Unit chief, YALE UNIVERSITY USA \\ *Corresponding author: Khaled Mohamed, Interim Unit chief, USA
}

Submission: 㰅 January 19, 2019; Published: 眥 February 07, 2019

\section{Opinion}

Sitting and listening to "Physician Wellness and Physician Suicide at Firkin Amphitheater, Yale university. Suddenly, my memory went back to 1996 . When I finished residency and started my first job at small community center in small town in Kentucky. I was the only psychiatrist. Two months after starting, a local psychiatrist who had been practicing for a long time lost his wife after struggling with cancer, Committed suicide" by shooting himself in the head. As it is a small town this was powerful event affected the whole community, as for me personally, although I did not know him personally, but as fellow psychiatrist, with my vulnerability moving to a new town with very little social support, I felt exposed, fearful, lonely. I could not stop thinking that one day it could be me, with the isolation I am experiencing there.

I used to see new patients early in the morning, then after that I see follow-ups. A few days later, a female patient entered the office, asking her about her name she introduced herself, saying that she was a patient of Dr. X who killed himself!

I was not prepared for such a thing or maybe I did not want to think that this would happen, I looked to her eyes, I saw fears, the first thing she told me was she is the patient of Dr. X who killed himself, I saw in her eyes that she wants me to tell her that I will not kill myself, then she did not give me the chance, she directly asked me "are you going to kill yourself?"

This was the last question I ever imagined that I would be asked from a patient. In residency training we never been trained to answer such a question. We are not supposed to answer questions directly, this patient had been traumatized by losing her psychiatrist the way we psychiatrists been traumatized in the past by losing our patients, that is why she is cautious to ask as an experienced psychiatrist about suicidality. Which in any board exam is pass and fail question? So, why I fail her for asking this question now. Did the psychiatrist by committing suicide abandoned the patient by early termination of therapy? Consequently, does this mean that the patient has the right every time to have a guarantee that the psychiatrist will be available next session. So what is the patient asking now that I will not kill myself is fair right bona fide of a contract which is the patient's right to know . But is it ethical to promise such a thing? I was afraid that I would kill myself a few days ago with all the insecurities I had been through, and the loneliness which I am experiencing. Can I promise her such a thing? We learned that we are not supposed to answer personal questions, but what is personal, Dr. X life affected all these patients, his own life is not personal. What is personal in psychiatrist life, if our own life is not personal, do we really have personal life.

This was just a beginning of a continuous struggle with flow of patients from his practice one after another. They were all afraid of trusting me, they wanted guarantee that I will not leave them or abandoned them. They all felt like a father figure was destroyed in front of them. One of the patients told me when he saw the psychiatrist last time, he asked him if he was sleeping with his suit because it looked like he did not change it for 7 days.

Every time I remember the graphic memory which was described to me when the doctor was found, and the mess of office, the brain parts all over the place, I feel so sad. That as strange as it may be, if that patient who noticed the suit was so dirty, asked the psychiatrist if he was suicidal, maybe things would be different. 
Creative Commons Attribution 4.0 International License

For possible submissions Click Here

PPRS

Psychology and Psychotherapy:
Research Study

cc) (1)

Submit Article

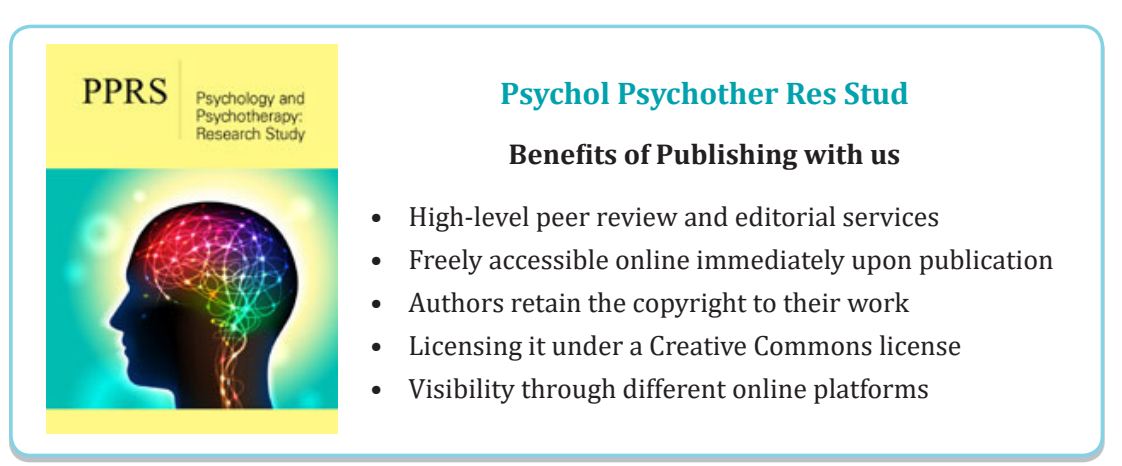

